\title{
The Evolution of the Overall Income Gap in the Process of Urbanization in China
}

\author{
Du Yaole \\ International Business School, Shaanxi Normal University \\ Xi'an, China \\ 1300856606@qq.com
}

\begin{abstract}
The academic circles have different opinions on the trend of the overall income gap in the process of urbanization. This paper adopts the Eviews empirical test method and draws the following conclusion: with the acceleration of urbanization process, the overall income gap of the residents in China appears to expand first and then reduce, showing a trend of inverted $U$ shape, the urban-rural income gap and urban-town income gap are the main reasons for the change in the overall income gap. Accordingly, it is suggested that in the process of promoting urbanization, we should synchronously promote the citizenship of migrant workers, the modernization of agriculture and the process of anti-urbanization.
\end{abstract}

Keywords-Urbanization; Citizenization; modernization; Reverse urbanization; Income gap

Agricultural

\section{INTRODUCTION}

The development of urbanization has a leading role in expanding domestic demand, improving production efficiency and promoting the optimal allocation of essential resources, and helps to improve the people's sense of gain. However, we should not neglect the problem of widening the overall income gap in the process of urbanization. The urbanization rate of our country has increased from $17.92 \%$ in 1978 to $57.35 \%$ in 2016 , and the level of urbanization has surpassed the world average level. At the same time, the overall income gap in China is also changing, according to the Statistics Bureau, from 1978 to 2015, the Gini coefficient has risen from the first 0.298 to 0.491 in 2008. (See Figure 1)Although it has declined since 2008, it is still in the 0.4-0.5 range. According to the relevant international regulations, the overall income gap in China is still relatively large.

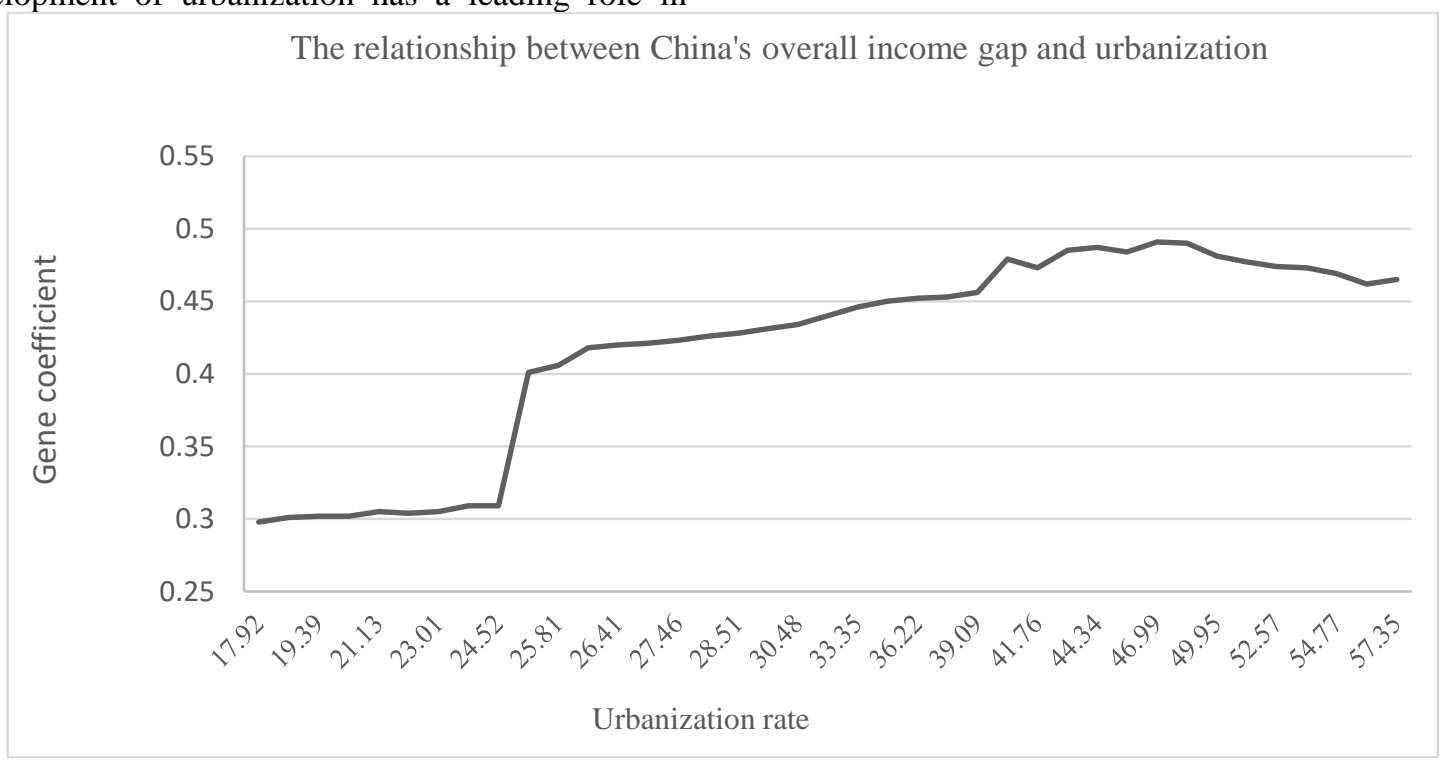

Fig. 1 The relationship between China's overall income gap and urbanization

The overall income gap of residents is not only related to social equity, but also greatly affects people's well-being. Since the reform and opening up, all previous National Congress of the Communist Party of China have not forgotten to mention the issue of income distribution. From the implementation of the single distribution of labor according to work to distribution according to work and distribution according to the distribution of factors of production, the goal of promoting common prosperity by the promotion of a small number of people and now to promote common prosperity is enough to see that the country is able to guarantee social equity. To promote the integration of urban and rural areas.

At present, the academic circles have different opinions on the relationship between the acceleration of urbanization and the change of the overall income gap. Shao Hongwei, Jin Tao (2016) [1] Through empirical tests, it is put forward that with 
the development of economy, the distribution of income presents an inverted $U$ trend. He Haoran(2013)[2]Using China's 2000-2010 year provincial panel data and the fixed effect model of panel variable coefficient points out that the improvement of urbanization level in China is beneficial to the narrowing of the income distribution gap. Wang Shaoping, Zhi-Gang Ouyang $(2007)^{[3]}$ Based on the data research between 1978-2008 years after China's reform and opening up, it is found that there is a positive correlation between the level of urbanization and the income gap. Based on the data of urbanization rate and Gini coefficient of 1978-2015 years in China, this paper proves that the change trend of the overall income gap in the process of urbanization in China accords with the "inverted U" curve of Kuznets, and combines the data of 2000-2015 years to analyze the reasons that affect the overall income gap and put forward some suggestions.

\section{AN EMPIRICAL STUDY OF INCOME GAP}

Urbanization rate is the representative of urbanization (X)in this paper, using Gini coefficient to show the overall income gap(Y).Based on the data of 1978-2015 years, the trend of overall income gap of Chinese residents is discussed with the increase of urban population.

In Figure 1, we can see that $\mathrm{X}$ and $\mathrm{Y}$ show a trend of "inverted U". Therefore, it is assumed that there are two functions as in:

$$
Y=\beta_{1} X+\beta_{2} X^{2}+\varepsilon
$$

Among them $\beta_{1}, \beta_{2}, \varepsilon$ are the parameters' to be estimated.

\section{A. Unit root test}

Because the data type belongs to the time series data, in order to ensure the credibility of the test results and avoid the phenomenon of pseudo regression, we need to do a stationary test for the data. This paper used ADF test and the results are as follows:

TABLE I The results of the first difference test for $Y$

\begin{tabular}{|c|c|c|c|}
\hline & & t-Statistic & Prob.* \\
\hline \multicolumn{2}{|l|}{ Augmented Dickey-Fuller test statistic } & -3.526668 & 0.0130 \\
\hline \multirow[t]{3}{*}{ Test critical values: } & $1 \%$ level & -3.632900 & \\
\hline & $5 \%$ level & -2.948404 & \\
\hline & $10 \%$ level & -2.612874 & \\
\hline \multicolumn{4}{|c|}{ he results of the second order difference test for X } \\
\hline & & t-Statistic & Prob.* \\
\hline-9.477610 & 0.0000 & & \\
\hline \multirow[t]{3}{*}{ Test critical values: } & $1 \%$ level & -4.243644 & \\
\hline & $5 \%$ level & -3.544284 & \\
\hline & $10 \%$ level & -3.204699 & \\
\hline
\end{tabular}

TABLE III The results of the second order difference test for $X^{2}$

\begin{tabular}{llcl}
\hline \hline & & & \\
Augmented Dickey-Fuller test statistic & & -8.107563 & 0.0000 \\
\hline Test critical values: & $1 \%$ level & -4.243644 \\
& $5 \%$ level & -3.544284 \\
& $10 \%$ level & -3.204699 \\
\hline \hline
\end{tabular}


The above results show that $Y$ satisfies the $\mathrm{I}(2)$ process, $\mathrm{X}$ and $X^{2}$ satisfies the $\mathrm{I}(2)$ process. The selected data is non-stationary and can not be directly analyzed by classical regression analysis. In order to deal with the regression problem of non-stationary data, we need further cointegration test.

\section{B. Cointegration test}

Because there are multiple variables in this model, Johansen test is applicable.

First of all, we need to establish the model with the most lagging order and establish the VAR model, assuming that the overall lag order is 5.Give the result as follows:

TABLE IV The overall optimal lag order of the model

\begin{tabular}{ccccccc}
\hline \hline Lag & LogL & LR & FPE & AIC & SC & HQ \\
\hline \hline & & & & & & \\
0 & 135.9239 & NA & $1.02 \mathrm{e}-06$ & -8.116602 & -8.025905 & -8.086085 \\
1 & 353.3033 & $395.2352^{*}$ & $2.48 \mathrm{e}-12$ & -21.04869 & $-20.77659^{*}$ & $-20.95713^{*}$ \\
2 & 357.5836 & 7.263558 & $2.45 \mathrm{e}-12^{*}$ & $-21.06567 *$ & -20.61219 & -20.91309 \\
3 & 361.3190 & 5.886002 & $2.51 \mathrm{e}-12$ & -21.04963 & -20.41475 & -20.83602 \\
4 & 362.6242 & 1.898553 & $3.00 \mathrm{e}-12$ & -20.88632 & -20.07004 & -20.61166 \\
5 & 368.8414 & 8.289638 & $2.68 \mathrm{e}-12$ & -21.02069 & -20.02302 & -20.68501 \\
\hline \hline
\end{tabular}

According to the AIC criterion, the optimal lag order of the model is 2. On this basis, Johansen test is carried out:

TABLE V Model cointegration test results

\begin{tabular}{ccccc}
\hline \hline Hypothesized & & & \\
No. of CE(s) & Eigenvalue & $\begin{array}{c}\text { Trace } \\
\text { Statistic }\end{array}$ & Critical Value & Prob.** \\
\hline \hline None * & 0.456058 & & & 0.05 \\
At most $1 *$ & 0.405235 & 19.58719 & 29.79707 & 0.0128 \\
At most 2 & 0.030653 & 1.089631 & 15.49471 & 0.2966
\end{tabular}

Therefore, cointegration relationship between variables in the model. There is a long-term stable relationship between $\mathrm{Y}$ and $\mathrm{X}, \mathrm{Y}$ and $X^{2}$. The relationship between them is:

\begin{tabular}{|c|c|c|}
\hline $\mathrm{Y}$ & $\mathrm{X}$ & $\mathrm{X}^{\wedge} 2$ \\
\hline 1.000000 & -3.512802 & 3.751594 \\
\hline & $(0.29013)$ & $(0.36757)$ \\
\hline
\end{tabular}

This confirms that with the development of urbanization, the overall income gap of residents presents a "inverted U" trend.

\section{Result analysis}

The test shows that the development trend between urbanization and the overall income gap in China basically meets the "inverted U" curve hypothesis proposed by Kuznets: The income gap presents an inverted $U$ development with the development of the economy. This is a phenomenon in many countries, that is, a process in which income distribution first deteriorates and then improves. With the acceleration of urbanization in China, the income distribution gap begins to decline after 2009, but there are many controversies about the gap will not continue to decline in the future. This paper argues that Kuznets's inverted $U$ curve will not be automatically realized. It still needs close attention and good management. At present, in the process of promoting urbanization, we should not only focus on urban construction, but also ignore the development of human beings. We need to reduce the overall income gap of residents.

\section{THE REASONS THAT AFFECT THE OVERALL INCOME GAP}

From a macro perspective, the reasons that affect the overall income gap can be divided into urban and rural income gap, urban internal income gap and rural internal income gap. In the study of the inner relationship between the urban and rural income gap, this paper measured the gap of urban and rural income by the ratio of urban and rural income; measured the gap of urban/rural internal income by the ratio of $20 \%$ high income groups and $20 \%$ low income groups. In view of the lack of statistical data of urban income grouping from 1978 to 1999, this paper selects data for 2000-2015 years to conduct research.

In order to study the change of the income gap between urban and rural areas leading to the change of the overall income gap, that is, the concept of marginal, we will establish a linear model:

$$
Y=\alpha X_{1}+\mu
$$

Among them, $\alpha, \mu$ are the parameters to be estimated. $X_{1}$ representatived the income gap between urban and rural areas, $\mathrm{Y}$ representatived overall income gap of Chinese 
Residents.

\section{A. Unit root test}

This paper used ADF test and the results are as follows:

TABLE VI The results of the second order difference test for $\mathrm{Y}$

t-Statistic Prob.*

\begin{tabular}{|c|c|c|c|}
\hline Augmented Dickey & -Fuller test statistic & -4.068189 & 0.0466 \\
\hline \multirow[t]{3}{*}{ Test critical values: } & $1 \%$ level & -5.295384 & \\
\hline & $5 \%$ level & -4.008157 & \\
\hline & $10 \%$ level & -3.460791 & \\
\hline
\end{tabular}

From the $\mathrm{P}$ value, Y satisfies the I (2) process.

TABLE VII The results of the second order difference test for $X_{1}$

\begin{tabular}{lccc}
\hline \hline & t-Statistic & Prob.* \\
\hline \hline Augmented Dickey-Fuller test statistic & -4.931937 & 0.0109 \\
\hline Test critical & 1\% level & -4.992279 & \\
values: & 5\% level & -3.875302 & \\
& 10\% level & -3.388330 & \\
\end{tabular}

From the P value, $X_{1}$ satisfies the I (2) process.

The results show that the selected data are non-stationary and can not be directly regression analysis. In order to deal with the regression problem of nonstationary sequences, it is necessary to do further cointegration test.

B. Cointegration test

From the above unit root test, it is found that two variables exist in the same order. Cointegration test using EG test: first, determine the residual time series, and then carry out the ADF unit root test for the residual sequence. Give the result as follows:

TABLE VIII ADF test results of residual sequence

\begin{tabular}{lccc}
\hline \hline & t-Statistic & Prob.* \\
\hline \hline Augmented Dickey-Fuller test statistic & -2.386175 & 0.0210 \\
\hline Test critical & 1\% level & -2.728252 & \\
values: & 5\% level & -1.966270 & \\
& 10\% level & -1.605026 & \\
\end{tabular}

$\overline{\text { The results show that the residual sequence is stable, so it }}$ can be concluded that there is a cointegration relationship between the two variables in the model, that is, there is a long-term stable proportion of the two variables in the model, and the results show that there is a positive correlation between the two variables.

The correlation between the urban / rural internal income gap and the overall income gap is consistent with the above research methods. The results show that there is a positive correlation between the urban internal income gap and the overall income gap, but there is no cointegration relationship between the rural internal income gap and the overall income gap at the 5\% significant level. Therefore, the income gap between urban and rural areas and the internal income gap between cities and towns are the main reasons leading to the change of the overall income gap.

\section{CONCLUSIONS AND SUGGESTIONS}

Urbanization is the inevitable choice to solve the prominent contradictions in the current economic and social development of our country and is an important driving force to promote the sustained economic growth of our country in the future. The rapid and good development of urbanization has reduced the bottom of the income base of the "gourd shape", and the bottom income is gradually increasing and narrowing. From the "gourd shape" to the "olives", it will help to reduce the overall income gap and reach a well-off people. Suggestions are made as follows:

\section{A. Promoting the citizenization of migrant workers}

According to incomplete statistics, 234 million of the urban population and their families are difficult to integrate into the urban society, and the process of urbanization is lagging behind. In the process of urbanization in many parts of China, the phenomenon of "heavy goods and light people" exists in varying degrees, ignoring the essential nature of the people-oriented nature of urbanization with Chinese characteristics.

First, with the development of urbanization, the demographic dividend will gradually disappear and usher in the "Curse of population". In view of this, on the basis of guaranteeing the equal education right of the children of the migrant workers, it will further strengthen the study of the basic skills for the migrant workers, enhance the innovative ability of the labor force as a whole, improve its competitiveness in the labor market, and narrow the income gap within the town. Secondly, more financial expenditure should be used in social security, focusing on residents with relatively low per capita income level and building a fair and equal social security system covering the whole people.

\section{B. Promoting the modernization of Agriculture}

Taking the road of new urbanization, we must put the modernization of agriculture in an important position. First of all, the improvement of agricultural technology will generate a large number of surplus labor force, thereby speeding up the flow of population to cities and towns. Secondly, agricultural modernization has huge demand for agricultural machinery, fertilizers, pesticides and other industrial products, and expands market space for new urbanization. Most importantly, raising the level of agricultural modernization has increased the marginal income of farmers and narrowed the income gap between urban and rural areas.

To improve the level of agricultural modernization, the following measures can be taken: First, build a high-yield and efficient production technology system and transform the mode of agricultural development. Demand oriented, improve the production and management technology of breeding industry, improve the quality of agricultural products and 
market competitiveness. Second, expand the various functions of agriculture. For example, according to local culture, farm family music and picking garden are developed to promote the organic combination of the first industry and the third industry; poultry and livestock are raised in the farm, and the effective integration of planting and breeding is promoted. Third, promote the use of e-commerce in agriculture. The government should encourage large business enterprises to go to the countryside while supporting the use of e-commerce platforms. Focus on promoting e-commerce platform to set up an agricultural electricity business area to achieve "one village, one product" online sales of agricultural products.

\section{The Implement of "reverse urbanization"}

The "reverse urbanization" strategy has been implemented in the United States, Britain and Germany, and the counter urbanization and urbanization are not antagonistic to each other, but the urbanization has developed to a certain stage. In order to alleviate the "urban disease", such as traffic congestion and environmental pollution, it has a promoting effect on urbanization. The government needs to take the lead in the implementation of "reverse urbanization" in China, and transfer the government departments or their subordinate institutions to small towns to drive the infrastructure construction of small towns and narrow the gap with the large and medium-sized cities. Secondly, we should actively encourage public institutions and enterprises to develop to small towns, for example, to guide colleges, institutes, museums and other public institutions to set up a standing point in small towns and attract more enterprises to develop in small towns. From the process of "reverse urbanization", the development of small towns and rural economy will be promoted, and the income gap between urban and rural areas will be narrowed.

\section{REFERENCES}

[1] Shao Hongwei, Jin Tao, The Kuznets inverted U curve of income distribution - the re-Empirical of cross-cross section and panel data. The fourth phase of China's industrial economy.2016.

[2] He Haoran, Education balance, urbanization level and residents' income gap.2013.

[3] Wang Shaoping, Ouyang Zhigang, Measurement of the income gap between urban and rural areas in China and its effect on economic growth.Economic research.2007,42(10):44-55.

[4] Gu Yan, Straighten out the relationship between income distribution in the process of urbanization. China price. 2013(05):7-11.

[5] Nie Hongtian. An Empirical Study on the impact of urbanization in China on the income gap between urban and rural areas .Liaoning University.2016.

[6] Ferrer - i - Carbonell, Income and Well - Being: An Empirical Analysis of the Comparison Income Effect. Journal of Public Economics, 2005, 89, 997-1019. 